This item was submitted to Loughborough's Institutional Repository by the author and is made available under the following Creative Commons Licence conditions.

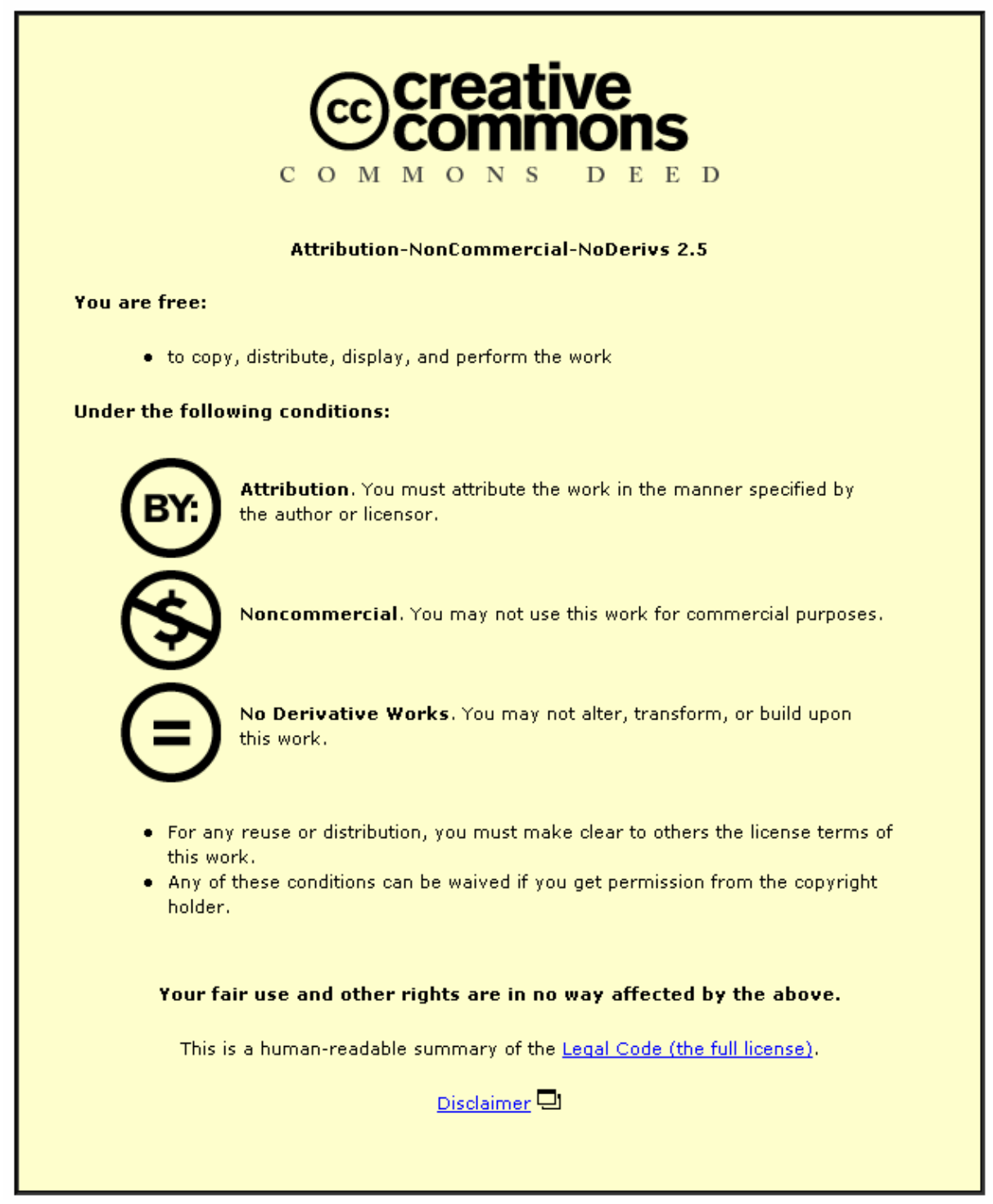

For the full text of this licence, please go to: http://creativecommons.org/licenses/by-nc-nd/2.5/ 


\title{
The Effect of Precipitated Calcium Carbonate on the Mechanical Properties of Poly(vinyl chloride).
}

\author{
N A S Fernando and N L Thomas \\ Institute of Polymer Technology \& Materials Engineering, Loughborough University, \\ Loughborough, Leicestershire, LE11 3TU, UK.
}

\section{Abstract}

This study examines the effect of various grades of precipitated and ground calcium carbonate on the tensile strength and Charpy impact energy of extruded PVC profile. The results confirm that ultra-fine precipitated calcium carbonate (pcc) can give rise to large improvements in single notch impact strengths. Control values of $9 \mathrm{kJm}^{-2}$ were increased to $79 \mathrm{kJm}^{-2}$ through the addition of ultra-fine pcc. The results have been interpreted in terms of the particle size, shape and coating of the calcium carbonate grades and the effect on the gelation characteristics of the PVC formulations. 


\section{INTRODUCTION}

Ultra-fine precipitated calcium carbonate is added as a functional filler to PVC formulations where it can be considered to act as a processing aid [1]. The primary particle size of these ultra-fine grades is in the range of $50-500 \mathrm{~nm}$. Such fine particles are comparable in size with primary particles of PVC $(0.2-1.0 \mu \mathrm{m})$ and hence are capable of generating interparticle friction with PVC particles, increasing shear and promoting gelation, which will be further investigated in this study.

Precipitated calcium carbonate (pcc) is synthesized by calcination of $\mathrm{CaCO}_{3}$ at $900^{\circ} \mathrm{C}$ to generate quick lime $(\mathrm{CaO})$, which is then mixed with water to form slaked lime $\left(\mathrm{Ca}(\mathrm{OH})_{2}\right)$. The slaked lime is reacted with $\mathrm{CO}_{2}$ from the calcination process to form pcc of difference morphologies depending on the precipitation conditions [1]. Fatty acid surface coatings are applied in the slurry stage before the filler is dried. The surface coating introduces hydrophobicity to the surface of the pcc and hence promote compatibility with polymers. The advantages of precipitated calcium carbonate are its fine particle size and narrow particle size distribution.

A number of authors [2-7] have reported that ultra-fine synthetic calcium carbonates can give rise to substantial improvements in impact strength, depending on the particle size and coating type. Results vary according to the PVC formulation and processing method used. However there is agreement that good dispersion of nano- $\mathrm{CaCO}_{3}$ can significantly enhance the toughness of rigid PVC.

In the current study, a number of different grades of pcc have been incorporated into a $\mathrm{Ca} / \mathrm{Zn}$ stabilised PVC window profile formulation. The effect of the pcc on the fusion characteristics and mechanical properties of the extruded PVC was examined. The results are interpreted in terms of the particle size, shape and coating of the calcium carbonate grades. 


\section{EXPERIMENTAL}

\section{Materials and Processing}

Four grades of precipitated calcium carbonate (pcc) were supplied by Solvay Advanced Functional Minerals with different particle size, shape and coating level. A grade of ground calcium carbonate (gcc) was supplied by Omya. Stearic acid was the surface coating agent. Information about the various grades in terms of their mean particle size, particle shape, specific surface area and percentage weight of coating is summarised in Table 1 and scanning electron micrographs are shown in Figure 1. Note that in the case of Grade G, which is scalenohedral in shape, the size quoted is the length of the crystals.

Dry blends were prepared with the formulation shown in Table 2 for each of the five different calcium carbonate grades. A control blend was also prepared without calcium carbonate. The PVC resin and other additives were blended simultaneously in a high speed Fielder mixer at $120^{\circ} \mathrm{C}$ at $2000 \mathrm{rpm}$ and then cooled to room temperature in the cooling chamber.

The fusion behaviour of the PVC dry blends was studied using a Haake Rheocord 90 torque rheometer. For each test $60 \mathrm{~g}$ of dry blend was charged into the chamber and mixing was carried out at a rotor speed of $60 \mathrm{rpm}$ and a temperature of $190^{\circ} \mathrm{C}$.

The Krauss Maffei KMD 25KK-L twin-screw extruder fitted with conical counterrotating screws was used to extrude the dry blends into profiles. A strip die was used with cross-section $4 \mathrm{~mm} \times 30 \mathrm{~mm}$. Extrusion was carried out using the set conditions shown in Table 3. 


\section{Differential Scanning Calorimetry}

The gelation (or fusion) level of PVC is known to have a significant effect on its mechanical properties $[8,9]$. Studies on the mechanism of gelation of PVC were first carried out by Summers [10]. It is now widely recognised that melting and recrystallisation of a proportion of the primary PVC crystallites is important in forming a network held together by tie molecules and secondary crystallinity. During processing, under the influence of both heat and shear, there is partial fusion of the primary crystallites and diffusion of macromolecules. During cooling recrystallisation occurs and the secondary crystallites help to link the primary particles together, so that the original PVC grain boundaries have disappeared.

Differential Scanning Calorimetry (DSC) is a useful technique for assessing PVC gelation level $[11,12]$. Figure 2 illustrates a typical DSC plot. Endothermic peaks on the DSC plot allow measurement of the proportions of primary (peak B) and secondary (peak A) crystallinity in a processed sample, and hence the degree of gelation (equation 1).

$$
\% \text { Gelation }=\left(\frac{\Delta \mathrm{H}_{\mathrm{A}}}{\Delta \mathrm{H}_{\mathrm{A}}+\Delta \mathrm{H}_{\mathrm{B}}}\right) \times 100 \%
$$

The true processing temperature can also be determined - see Figure 2.

DSC thermograms were recorded using a DuPont 2010 Thermal Analyser. Specimens of 10-12 mg were taken from the core of each extrudate. Specimens were heated from $40^{\circ} \mathrm{C}$ to $240^{\circ} \mathrm{C}$ at $20^{\circ} \mathrm{C}$ per minute.

\section{Mechanical Properties}

Tensile testing was carried out using a Hounsfield tensile testing machine according to British Standard 2782. Dumbbell shaped test specimens were tested at a strain rate of $25 \mathrm{~mm} / \mathrm{min}$. 
Impact testing was performed according to British Standard 7413 using a pendulum Charpy Impact tester. Specimens were prepared with a milling machine and notched with a single tooth cutter. A minimum of 12 specimens was tested for each formulation.

\section{RESULTS AND DISCUSSION}

\section{Gelation Measurements}

Results of time to gelation from the Haake Rheocord mixer are shown in Table 4. These results clearly show that all the calcium carbonate fillers have reduced the time to gelation, and the smaller the particle size the greater the effect. These results substantiate the claim that fine inorganic particles can promote gelation.

Differential scanning calorimetry (DSC) experiments on samples from extruded PVC profiles also confirm that the ultra-fine precipitated calcium carbonates (grades E, F and I) promote gelation, presumably by increased shear and inter-particle friction. It is seen from the results in Table 5 that formulations containing these grades have a significantly higher processing temperature, enthalpy of Peak A (melting of secondary crystallites) and \% gelation level than the unfilled formulation. It is interesting to note that grade I, with the finest particle size, has the highest processing temperature and gelation level.

\section{Mechanical Properties}

Figure 3 shows the results of tensile strength measurements of the various formulations. This bar chart includes the error bars of the data and it can be seen that, excluding grade $\mathrm{G}$, all the formulations have a tensile strength of around 41-42 $\mathrm{MPa}$ and there is no significant difference between them. The formulation containing grade G, however, has a significantly lower tensile strength of about $30 \mathrm{MPa}$. Grade $\mathrm{G}$ was the coarsest filler used and had no stearic acid coating. The decrease in tensile strength is thought to be due to poor 
adhesion between the filler particles and the matrix, due to the lack of coating on the filler particles.

Results of elongation-to-break from the tensile tests are plotted as a function of filler particle size in Figure 4. From this data it is clear that elongation-to-break, and hence the ductility of the samples, increases with decreasing particle size. The three ultra-fine pcc grades all have significantly increased elongation-to-break with the highest value being for grade I at $97 \%$. The unfilled control has a value of $30 \%$ whereas grade $\mathrm{G}$, with a coarse particle size, is down at $12 \%$.

The effect of filler particle size on the Charpy impact strength of the extruded profiles is plotted in Figure 5. The data exactly mirror the trend found in Figure 4 - namely that reducing particle size gives an improvement in toughness of the PVC profiles. Addition of coated fillers of particle size less than 1 micron all improve the Charpy impact strength and the finer the filler the greater the improvement. The unfilled profile has an impact strength of $9 \mathrm{~kJ} / \mathrm{m}^{2}$ and this increases to $79 \mathrm{~kJ} / \mathrm{m}^{2}$ for the formulation containing the finest particle size filler (grade I). Grade G, however, reduces the Charpy impact strength to $6 \mathrm{~kJ} / \mathrm{m}^{2}$.

Scanning electron micrographs of the fracture surfaces of the impact specimens were recorded. Typical fracture surfaces from two different samples are compared in Figure 6. Figure 6(a) shows the fracture surface from a sample containing grade H. Incorporation of grade $\mathrm{H}$ was found to give a significant improvement in impact strength, increasing to 16 $\mathrm{kJ} / \mathrm{m}^{2}$ compared with $9 \mathrm{~kJ} / \mathrm{m}^{2}$ for the unfilled control. It can be seen that the fracture surface has a cratered, featureless appearance that is characteristic of brittle failure and rapid crack propagation. Filler particles are visible on the surface. Although this is a brittle failure, addition of fine filler particles have caused toughening by what appears to be a cavitation mechanism. This mechanism requires moderate adhesion between the calcium carbonate 
particles and the PVC matrix. The optimum degree of adhesion is provided by the stearic acid coating.

Figure $6(\mathrm{~b})$ is the fracture surface from the formulation containing grade I. The morphology seen here consists of fibrils of highly strained, cold drawn PVC and is indicative of ductile failure. This micrograph clearly shows that the PVC matrix has absorbed the additional energy and has failed by a ductile mechanism. Other workers (8) have reported similar fibrillar microstructures found in impact modified PVC, where ductile yielding and fibrillation was associated with crack blunting. In the present case it is clear that addition of ultra-fine pcc has given rise to micro-crazing and fibrillation, and that the failure mode in impact testing has switched from brittle to ductile. This is reflected both in the morphology of the fracture surfaces as well as the very high impact energies measured.

It is interesting to note from both Figures 4 and 5 that the critical particle size below which improvements in toughness (both elongation-to-break and impact energy) would be expected to occur is about 1 micron.

\section{CONCLUSIONS}

This study confirms that ultra-fine grades of precipitated calcium carbonate can act as processing aids in a $\mathrm{Ca} / \mathrm{Zn}$ stabilised rigid PVC formulation. Results from tests in the Haake torque rheometer showed that all the calcium carbonate fillers reduced the time to gelation of PVC dry blends and the smaller the particle size the greater the effect. Similarly results from DSC experiments on extruded PVC profiles confirmed that ultra-fine pcc grades promote gelation. Formulations containing these grades had a significantly higher processing temperature, $\Delta \mathrm{H}_{\mathrm{A}}$ and $\%$ gelation level than the unfilled formulation.

The tensile strengths of extruded profiles were unaffected by the addition of calcium carbonate fillers except in the case of grade $\mathrm{G}$, which was the coarsest filler investigated and 
without a stearic acid coating. In this case there was found to be a significant reduction in tensile strength, which was attributed to poor adhesion between the filler particles and the matrix.

Elongation-to-break, and hence the ductility of the samples, increased with decreasing particle size. The trend was also mirrored in results of impact tests: namely that the finer the particle size the greater the impact strength. The unfilled profile had an impact strength of 9 $\mathrm{kJ} / \mathrm{m}^{2}$, which increased to $79 \mathrm{~kJ} / \mathrm{m}^{2}$ for the formulation containing the finest particle size filler

(grade I). Scanning electron micrographs confirmed that the impact behaviour had switched from brittle behaviour for the coarser grades of calcium carbonate to a ductile mode for the ultrafine grades.

\section{ACKNOWLEDGMENTS}

The authors would like to acknowledge funding for this work from Solvay Advanced Functional Minerals and from the Engineering and Physical Sciences Research Council, UK (EPSRC). Technical support from Mr David Cornwell and Ms Gaelle Rodary of Solvay Advanced Functional Minerals has been much appreciated. 


\section{REFERENCES}

1. D. W. Cornwell \& G. Rodary, Plastic, Rubbers and Composites: Macromolecular Engineering 34 (2005) 105.

2. $\quad$ K. Mathur, L. Rogers and M. Tapper, J Vinyl Technol., 8 (1986) 120.

3. N. Chen, C. Wan, Y. Zhang \& Y. Zhang, Polymer Testing 23 (2004) 169.

4. L. Zhang, X. Chen \& C. Li, J Mat Sci Letters 40 (2005) 2097.

5. M. Vučak \& H-D. Stöver, Kunststoffe Plast Europe 2 (2005) 1.

6. S. Sun, C. Li, L. Zhang, H. L. Du \& J. S. Burnell-Gray, Polym Int 55 (2006) 158.

7. C. Jianfeng, J. Yun \& W. Guoquan, Modern Plastics 79 (2002) 64.

8. B. Cora, B. Daumas and A. Zegers, Plast. Rubber Compos., 28, 165 (1999)

9. N. L. Thomas and R. J. Harvey, Plast. Rubber Compos.,

10. J. W. Summers, J Vinyl Technol., 3, 107 (1981)

11. M. Gilbert and J. C. Vyvoda, Polymer, 22, 1134 (1981)

12. L-A. Fillot, P. Hajii, C. Gauthier and K. Masenelli-Varlot , J Vinyl \& Additive Technol, 12, 98 (2006)

13. A. Hassan \& B. Haworth, J Materials Processing Technology 172 (2006) 341. 
TABLE 1. Properties of Calcium Carbonate Grades

\begin{tabular}{|l|c|c|l|c|}
\hline \multicolumn{1}{|c|}{ Type/Grade } & $\begin{array}{c}\text { Mean } \\
\text { Particle } \\
\text { Size }(\mu \mathrm{m})\end{array}$ & $\begin{array}{c}\text { Coating Level } \\
\text { (weight \%) by } \\
\text { CHN Analysis }\end{array}$ & Particle Shape & $\begin{array}{c}\text { Specific } \\
\text { Surface Area } \\
(\mathrm{BET}) \mathrm{m}^{2} / \mathrm{g}\end{array}$ \\
\hline PCC-Grade E & 0.06 & 2.3 & Rhombohedral & 19.0 \\
\hline PCC-Grade F & 0.07 & 2.6 & Rhombohedral & 20.8 \\
\hline PCC-Grade G & 1.2 & 0 & Scalenohedral & 8.9 \\
\hline GCC-Grade H & 0.85 & 1.6 & Irregular & 10.1 \\
\hline PCC-Grade I & 0.055 & 2.9 & Rhombohedral & 23.6 \\
\hline
\end{tabular}

TABLE 2. Formulation

\begin{tabular}{|l|c|}
\hline Ingredient & $\begin{array}{l}\text { Concentration }- \text { Parts per hundred parts } \\
\text { of polymer (phr) }\end{array}$ \\
\hline Poly(vinyl chloride) - K66 & 100 \\
\hline Acrylic Impact Modifier & 7 \\
\hline Ca/Zn Thermal Stabiliser & 4.5 \\
\hline Acrylic Processing Aid & 1.0 \\
\hline Titanium Dioxide Pigment & 4 \\
\hline Calcium Carbonate Filler & 10 \\
\hline
\end{tabular}

TABLE 3. Extrusion Conditions on the Krauss Maffei KMD 25KK-L

\begin{tabular}{|c|c|c|c|c|c|}
\hline $\begin{array}{c}\text { Die } \\
\text { Temperature }\end{array}$ & $\begin{array}{c}\text { Adapter } \\
\text { Temperature }\end{array}$ & $\begin{array}{c}\text { Zone 2 } \\
\text { Temperature }\end{array}$ & $\begin{array}{c}\text { Zone 1 } \\
\text { Temperature }\end{array}$ & $\begin{array}{c}\text { Screw } \\
\text { Temperature }\end{array}$ & $\begin{array}{c}\text { Screw } \\
\text { Speed }\end{array}$ \\
\hline $200^{\circ} \mathrm{C}$ & $200^{\circ} \mathrm{C}$ & $190^{\circ} \mathrm{C}$ & $180^{\circ} \mathrm{C}$ & $150^{\circ} \mathrm{C}$ & $20 \mathrm{rpm}$ \\
\hline
\end{tabular}

TABLE 4. Time to Gelation of Dry Blends from Haake Rheocord Tests

\begin{tabular}{|l|c|}
\hline $\begin{array}{l}\text { PVC Blends containing the following filler } \\
\text { type:- }\end{array}$ & Time to Gelation in Seconds \\
\hline PCC-Grade E & $36.1 \pm 0.4$ \\
\hline PCC-Grade F & $36.3 \pm 0.5$ \\
\hline PCC-Grade G & $59.9 \pm 1.1$ \\
\hline GCC-Grade H & $48.1 \pm 0.19$ \\
\hline PCC-Grade I & $36.1 \pm 0.2$ \\
\hline No Filler & $79.2 \pm 6.6$ \\
\hline
\end{tabular}


TABLE 5. Results from Differential Scanning Calorimetry (DSC) Experiments

\begin{tabular}{|l|c|c|c|}
\hline $\begin{array}{l}\text { Extruded PVC sample } \\
\text { containing the following } \\
\text { filler }\end{array}$ & $\begin{array}{l}\text { Processing } \\
\text { Temperature }{ }^{\circ} \mathrm{C}\end{array}$ & $\begin{array}{l}\Delta \mathrm{H}_{\mathrm{A}}-\text { Enthalpy of } \\
\text { Peak A }(\mathrm{J} / \mathrm{g})\end{array}$ & \% Gelation \\
\hline PCC-Grade E & $191.1 \pm 0.63$ & $2.78 \pm 0.31$ & $86.8 \pm 0.5$ \\
\hline PCC-Grade F & $190.8 \pm 0.68$ & $2.95 \pm 0.11$ & $86.0 \pm 0.5$ \\
\hline PCC-Grade G & $190.3 \pm 0.46$ & $2.92 \pm 0.24$ & $85.8 \pm 1.2$ \\
\hline GCC-Grade H & $190.1 \pm 0.50$ & $2.43 \pm 0.05$ & $82.8 \pm 1.3$ \\
\hline PCC-Grade I & $193.3 \pm 0.24$ & $3.70 \pm 0.17$ & $89.3 \pm 1.3$ \\
\hline No Filler & $189.3 \pm 0.28$ & $2.55 \pm 0.16$ & $81.8 \pm 1.0$ \\
\hline
\end{tabular}

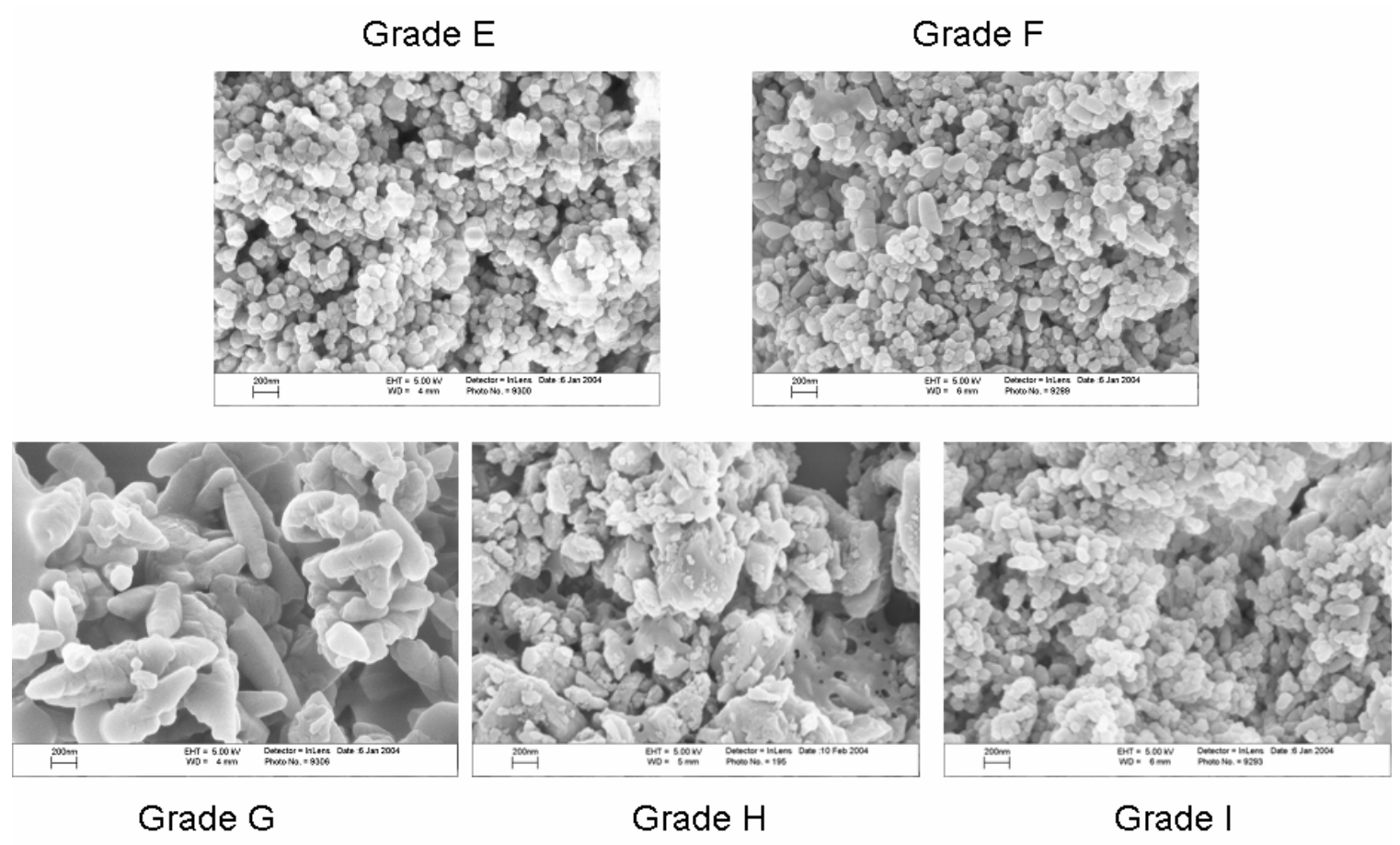

Figure 1. Scanning Electron Micrographs of Calcium Carbonate Grades 


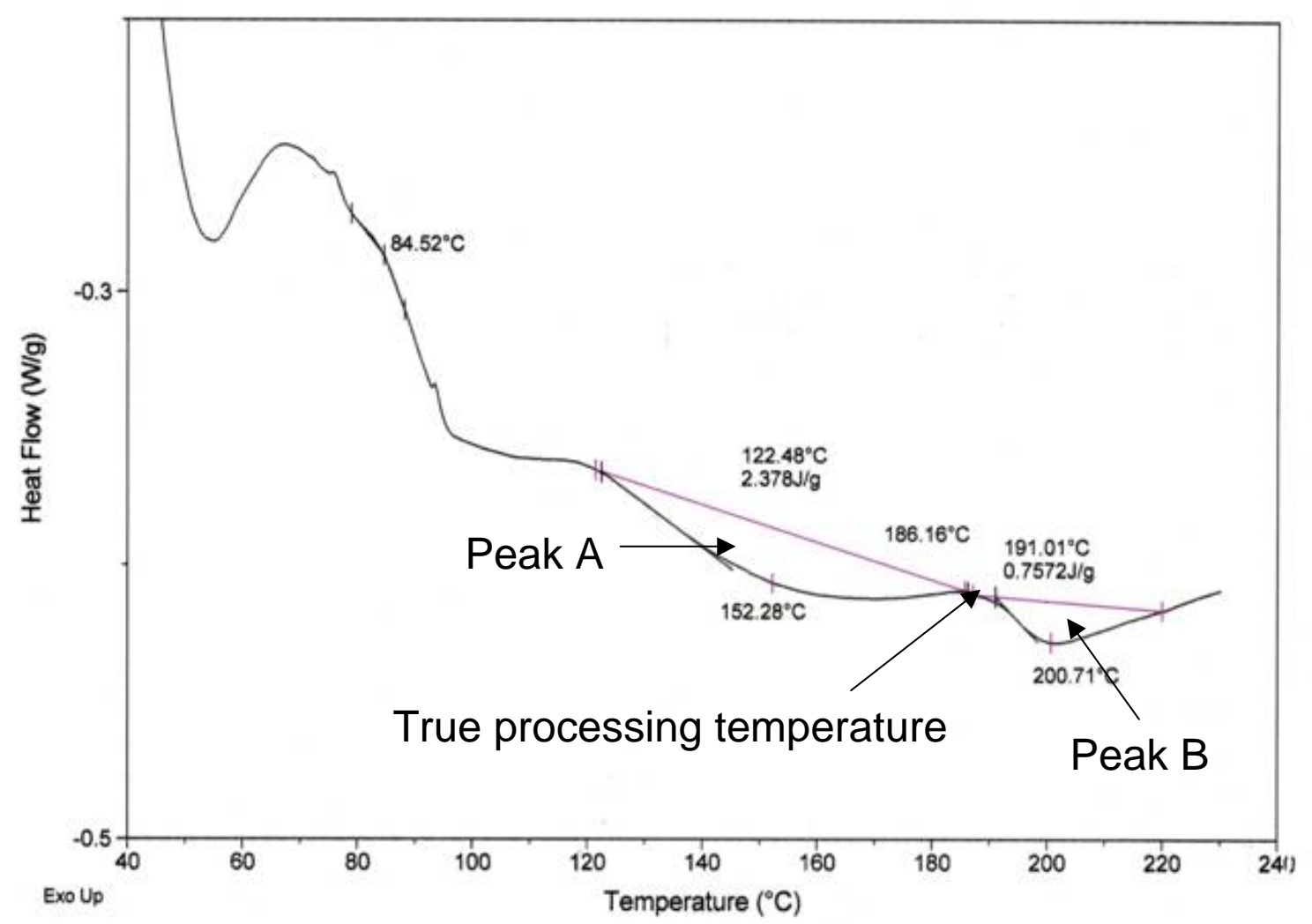

Figure 2. Typical DSC Plot of Extruded PVC showing the True Processing Temperature

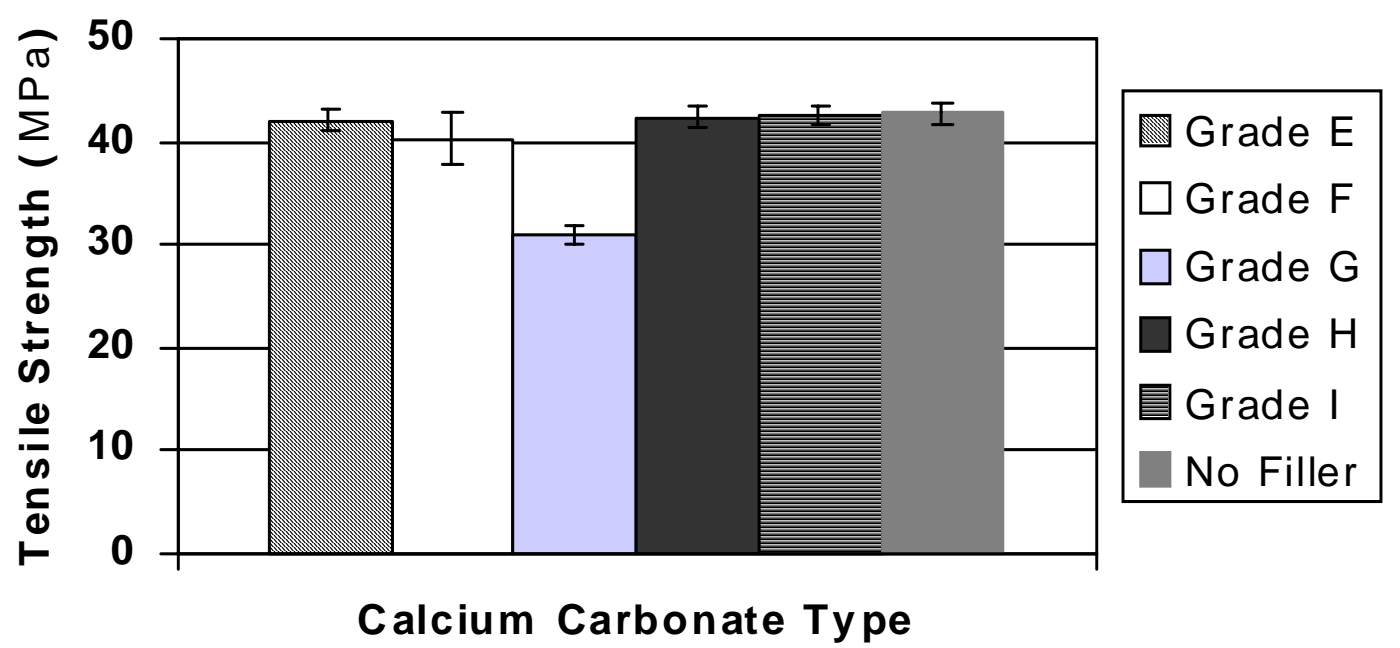

Figure 3. Tensile Strength Results from PVC Profiles containing different Calcium Carbonate Grades 


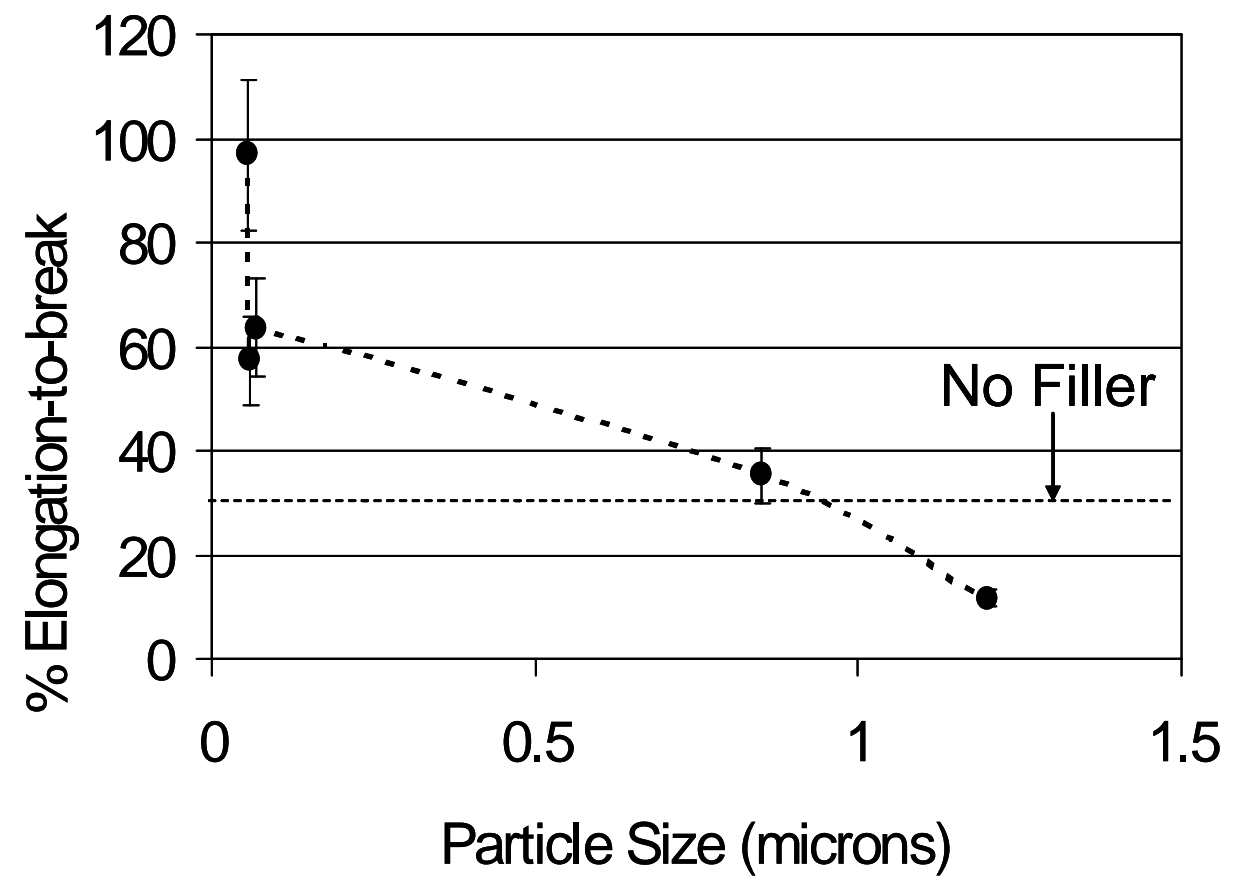

Figure 4. Effect of Calcium Carbonate Particle Size on the Elongation-to-break of Extruded PVC Profile

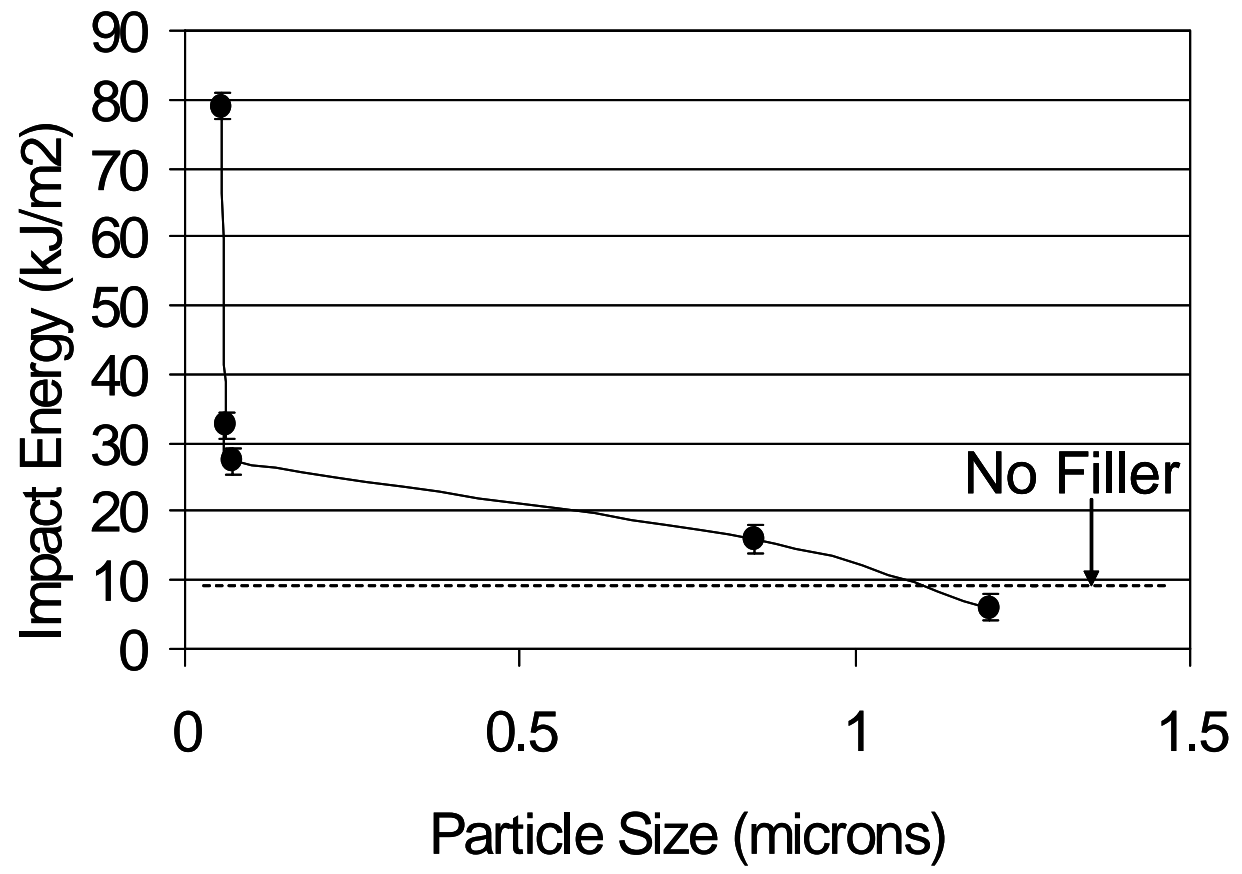

Figure 5. Effect of Calcium Carbonate Particle Size on the Impact Strength of Extruded PVC Profile (Single V-notch Charpy Test) 
(a) Brittle Failure $-16 \mathrm{~kJ} / \mathrm{m}^{2}$

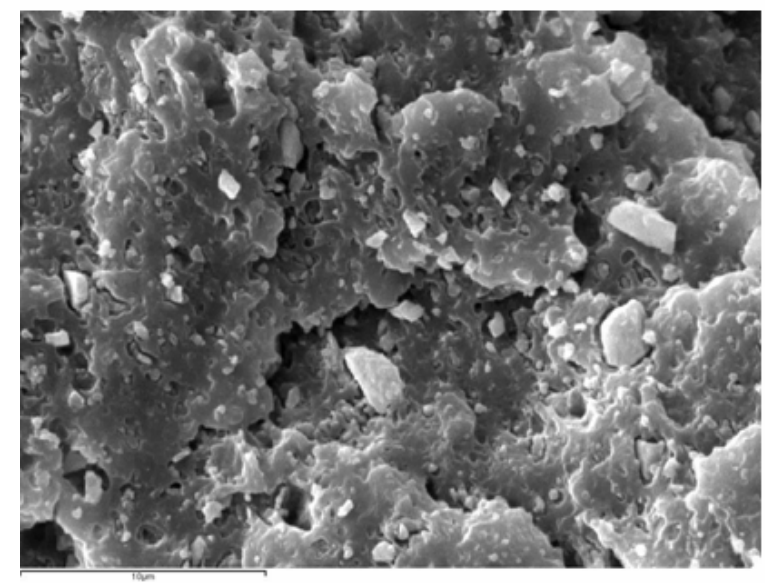

(b) Ductile Failure $-79 \mathrm{~kJ} / \mathrm{m}^{2}$

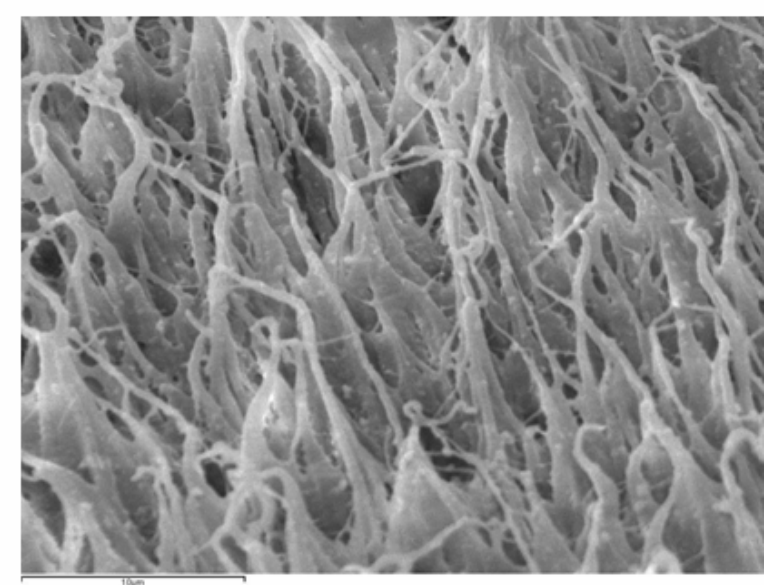

Figure 6. Scanning Electron Micrographs of Fracture Surfaces 